\title{
Government debt and aggregate stability with endogenous growth: Some general results
}

Alfred Greiner 


\title{
Government debt and aggregate stability with endogenous growth: Some general results
}

\author{
Alfred Greiner*
}

\begin{abstract}
We consider a general class of endogenous growth models with infinitely lived households and analyze how different budgetary rules affect the stability of the economy. We show that a discretionary fiscal policy implies that the government always violates its inter-temporal budget constraint along a balanced growth path, whereas a balanced budget rule tends to stabilize the economy. A rule based debt policy makes the economy converge to the balanced growth path provided the reaction of the primary surplus to higher public debt is sufficiently large so that the debt to GDP ratio becomes a mean-reverting process.
\end{abstract}

JEL: H6, O4

Keywords: Public debt, inter-temporal budget constraint, budgetary rules, stability, endogenous growth

${ }^{*}$ Department of Business Administration and Economics, Bielefeld University, P.O. Box 100131, 33501 Bielefeld, Germany, e-mail: agreiner@wiwi.uni-bielefeld.de 


\section{Introduction}

The current debt crisis in the Euro area drastically illustrates that excessive borrowing can endanger the stability of economies. This shows that the question of how public debt and deficit policies affect stability of market economies is not only of theoretical interest but has also practical relevance. With this note we intend to contribute to this line of research by analyzing the effects of different budgetary rules for a general class of endogenous growth models.

In the economics literature, there exists a line of research that analyzes how budgetary rules affect the stability of economies, starting with the contribution by Schmidt-Grohé and Uribe (1997). However, those papers present purely academic exercises rather than contributions that are of relevance for real world economies. The latter holds because they neglect two fundamental aspects: namely the fact that economies grow over time and the destabilizing effect arising from the accumulation of public debt by leaving aside the differential or difference equation that describes the evolution of debt. Looking at the current financial and public debt crisis in the real world, however, one realizes that the decisive aspect about public debt is that high deficits tend to make the debt to GDP ratio explosive, thus, jeopardizing the stability of the whole economy.

When the evolution of public debt and endogenous growth are explicitly taken into account, it often turns out that a balanced government budget tends to stabilize the economy in the sense that the economy is saddle point stable and converges to the balanced growth path (see e.g. Greiner, 2008, 2011). In the case of permanent deficits, however, convergence to the balanced growth path and, hence, stability often can only be guaranteed if the government puts a sufficiently high weight on stabilizing the public debt to GDP ratio. Otherwise, the economy may become unstable and for a certain range of the parameter, determining the reaction of the government to higher debt, the economy may be characterized by persistent endogenous growth cycles (see Greiner, 2007). With this contribution we intend to generalize the results derived for specific endogenous growth 
models by analyzing quite a general class of models featuring endogenous growth.

The rest of the paper is organized as follows. In the next section we present the structure of our model economy and we discuss the assumptions we make. Section 3 derives the results with respect to stability and presents an example and section 4, finally, concludes.

\section{Structure of the economy}

We consider a closed economy in continuous time that consists of a household sector, of a productive sector and of the government. ${ }^{1}$ First, we discuss the assumptions as concerns the household sector.

\subsection{The household sector}

The household sector consists of many infinitely lived households that maximize the discounted stream of utility resulting from private consumption over an infinite time horizon subject to their budget constraints. The solution to the optimization problem gives the growth rate of consumption, $C$, as (see e.g. Blanchard and Fischer (1989), chap. 2 for a detailed derivation),

$$
\frac{\dot{C}}{C}=\frac{r(1-\tau)-\rho}{\sigma}
$$

with $r$ the return to capital, $\tau \in(0,1)$ the income tax rate, $\rho>0$ the subjective rate of time preference and $1 / \sigma>0$ the inter-temporal elasticity of substitution of consumption. Without loss of generality we assume a constant labour supply and we neglect depreciation of capital. The return to capital is determined endogenously while $\tau, \rho$ and $1 / \sigma$ are parameters.

Labour supply is assumed to be exogenous. Allowing for an endogenous labour supply does not change the basic results but imposes constraints on the utility function when the

\footnotetext{
${ }^{1}$ We omit the time argument $t$ if no ambiguity arises.
} 
economy grows endogenously with a permanently rising wage rate (see for example the discussion in Benhabib and Farmer, 1994). It should be noted that in an endogenously growing economy the wage rate can be constant in the long-run when a purely public good, such as public health, affects both utility and production and grows in the long-run, too.

\subsection{The productive sector}

The productive sector behaves competitively and maximizes static profits such that the factor prices equal their marginal products. In particular, the return to capital, $r$, is equal to the marginal product of capital and constant in the long-run due to constant returns to the factors that can be accumulated.

\subsection{The government}

The government receives income tax revenues and runs into debt to finance lump-sum transfers to the household sector that may be positive or negative and to finance public spending. The period budget constraint of the government is given by,

$$
\dot{B}=r(1-\tau) B-S
$$

with $B$ public debt and $S=\tau Y-G_{p}-T_{p}$ the primary surplus, where $Y$ denotes GDP and $G_{p}$ and $T_{p}$ are public spending and transfer payments, respectively. It should be noted that we do not consider the case of a negative public debt implying that the government would be a creditor, i.e. we assume $B \geq 0$. Public spending may be productive, for example public investment, or it may yield utility for households. In the latter case, however, we assume that the utility function is additively separable in public and private consumption. Further, the government must stick to the inter-temporal budget constraint given by,

$$
\lim _{t \rightarrow \infty} e^{-\int_{0}^{t}(1-\tau) r(\mu) d \mu} B(t)=0
$$


As concerns the debt policy of the government, we consider three different types: First, a discretionary policy where the government sets the primary surplus arbitrarily. Second, a balanced budget where the primary surplus is set such that the level of public debt, $B$, remains constant. And, third, a rule based policy where the primary surplus is a positive linear function of public debt, relative to GDP respectively. The economic rationale behind that policy is that the government has to run primary surpluses in the future, when it incurs deficits today, in order to avoid playing a Ponzi-game. Further, there is very strong empirical evidence that governments indeed follow this rule, see e.g. Bohn (1998) for the USA and Greiner et al. (2007) for European economies. Formally, for the rule based policy the primary surplus relative to GDP is given by the following expression:

$$
\frac{S}{Y}=\phi+\psi\left(\frac{B}{Y}\right), \quad \text { with } \quad \phi \in \mathbb{R}, \psi \in \mathbb{R}_{++}
$$

The coefficient $\psi$ will be called the reaction coefficient since it determines how strong the primary surplus rises as public debt increases, relative to GDP respectively.

When the government raises its primary surplus it can either increase the distortionary income tax rate, reduce non-distortionary transfer payments to the private sector or reduce public spending. In this contribution, we assume that the income tax rate and public spending are left unchanged so that the government reacts by reducing transfer payments to the household sector. Thus, the economy-wide resource constraint is obtained as,

$$
\dot{K}=Y-C-G_{p}
$$

\subsection{The balanced growth path}

We assume that there exists a balanced growth path (BGP) for our model economy. This implies that the right-hand side of the differential equation system is strictly positive and does not dispose of a rest point. Typically, the dynamics around a BGP, then, are studied by dividing all variables by the physical capital stock and by differentiating these ratios 
with respect to time. A rest point of this new differential equation system gives a BGP for the economy. We assume that this procedure is also possible for the class of models we consider. In the next section, we analyze how the different debt policies affect stability of the economy in the sense of convergence to the BGP. But before, we give a concrete definition of balanced growth.

Definition A balanced growth path (BGP) is a path such that the economic variables, consumption, capital stocks and GDP, grow at the same strictly positive constant growth rate, $g$, and either (i) $\dot{B} / B=g$ or (ii) $\dot{B}=0$.

This definition shows that public debt either grows at the same rate as all other economic variables on a BGP or that it remains constant when the government runs a balanced budget.

\section{Implications of debt policies for stability}

We first look at the discretionary fiscal policy.

\subsection{Discretionary policy}

When the government pursues a discretionary fiscal policy where it sets the primary surplus arbitrarily, its inter-temporal budget constraint is always violated along a BGP. Proposition 1 gives the result.

Proposition 1 Assume that the government pursues a discretionary fiscal policy. Then, its inter-temporal budget constraint is violated along a BGP.

Proof: See appendix

The reason for the outcome in proposition 1 is that the debt to GDP ratio explodes when the government does not react to a rising public debt by increasing its primary 
surplus. In such a situation, sustainability is only given if the initial primary surplus is exactly set to a certain value that depends on the initial level of public debt. Then, however, the fiscal policy is not discretionary since it is determined by the level of initial debt and by other variables (see the appendix for details). An implication of this proposition is that the government must react in one way or another to rising debt to GDP ratios to prevent playing a Ponzi-game. Next, we study the balanced budget rule.

\subsection{The balanced budget rule}

When the government runs a balanced budget, the level of public debt remains constant and the debt to GDP ratio converges to zero since GDP permanently grows. This is the contents of proposition 2 .

Proposition 2 Assume that the government runs a balanced budget. Then, on a BGP the debt to GDP ratio asymptotically converges to zero. A balanced budget tends to stabilize the economy because with a balanced budget there always exists at least one negative eigenvalue.

Proof: See appendix

Thus, a balanced government budget prevents the debt to GDP ratio from exploding. Instead, the debt ratio declines over time which tends to stabilize the economy. That holds because with a balanced budget the Jacobian matrix evaluated at the rest point has at least one negative eigenvalue. Of course, the dynamics of the economy also depend on the concrete model under consideration but, nevertheless, the result in proposition 2 holds in general.

For sake of completeness we want to state that a debt policy such that public debt grows, but less than GDP in the long-run, is equivalent to that of a balanced budget with respect to stability and economic growth. That holds because in both scenarios the debt to GDP ratio converges to zero asymptotically. However, as concerns welfare the 
scenario with a slightly growing public debt, i.e. rising less than GDP, may perform better when transition dynamics are taken into account (see e.g. Greiner, 2008, for a model with productive public investment or Greiner, 2011, where public spending is welfare enhancing).

Next, we analyze the primary surplus rule based public debt policy.

\subsection{The primary surplus rule}

When the government follows the primary surplus rule given by equation (4), public debt evolves according to

$$
\dot{B}=r(1-\tau) B-\psi B-\phi Y
$$

Then, the reaction coefficient $\psi$ is decisive as concerns the dynamics of the debt to GDP ratio. Proposition 3 gives the result.

Proposition 3 When the government follows the primary surplus rule, the debt to capital ratio remains bounded if and only if $\psi>r(1-\tau)-g$ holds. One eigenvalue of the Jacobian matrix is equal to $r(1-\tau)-g-\psi$.

Proof: See appendix

Propostion 3 demonstrates that the debt to capital ratio and, thus, also the debt to GDP ratio remains bounded only if the reaction coefficient $\psi$ is sufficiently large. Concretely speaking, it must exceed the difference between the net interest rate on public debt and the balanced growth rate. That result is rather intuitive: When the debt to capital ratio rises, this implies that the net interest payments increase by $r(1-\tau)$. At the same time, the primary surplus rises at the rate $g$ since the primary surplus grows at the same rate as all other economic variables along the BGP. Hence, the debt to capital ratio will become explosive unless the government raises the primary surplus, relative to capital at least by that difference. It should be noted that in case of $r(1-\tau)<g$, which 
may occur for $1 / \sigma>1$, the economy can grow out of debt and the government can fulfill its inter-temporal budget constraint even with a non-positive reaction coefficient.

\subsection{An example}

We consider an economy with a productive public capital stock, $G$, that is the result of public investment. Without loss of generality we set $\sigma=1$. Since a discretionary policy inplies that the government plays a Ponzi-game, we will limit our investigations to the primary surplus rule and to the balanced budget rule. Then, the differential equation system that describes the economy is as follows,

$$
\begin{aligned}
\frac{\dot{C}}{C} & =-\rho+r(1-\tau), C(0) \\
\frac{\dot{K}}{K} & =\left(\frac{Y}{K}\right)\left(1-i_{p}\right)-\frac{C}{K}, K(0)=K_{0} \\
\frac{\dot{G}}{G} & =i_{p}\left(\frac{Y}{K}\right)\left(\frac{K}{G}\right), G(0)=G_{0} \\
\frac{\dot{B}}{B} & =r(1-\tau)-\psi-\phi\left(\frac{Y}{K}\right)\left(\frac{K}{B}\right), B(0)=B_{0},
\end{aligned}
$$

with $i_{p}>0$ the share of public investment relative to GDP that is controlled by the government. Setting $\phi=0$ and $\psi=r(1-\tau)$ yields the balanced budget rule. Aggregate output is given by $Y=K^{\alpha} G^{1-\alpha}$ yielding $r=\alpha(G / K)^{1-\alpha}$. Defining $y:=C / K, x:=G / K$ and $b:=B / K$ the modified differential equation system describing the economy around a BGP is obtained as,

$$
\begin{aligned}
\dot{y} & =y\left(-\rho+(1-\tau) \alpha x^{1-\alpha}+y-\left(1-i_{p}\right) x^{1-\alpha}\right) \\
\dot{x} & =x\left(i_{p} x^{-\alpha}+y-\left(1-i_{p}\right) x^{1-\alpha}\right) \\
\dot{b} & =b\left((1-\tau) \alpha x^{1-\alpha}-\psi-\phi b^{-1} x^{1-\alpha}+y-\left(1-i_{p}\right) x^{1-\alpha}\right) .
\end{aligned}
$$

There is a unique value $x^{\star}$ that solves the equation $i_{p} x^{-\alpha}+\rho-\alpha(1-\tau) x^{1-\alpha}=0$ that implies $\dot{x}=\dot{y}=0 .^{2}$ This gives a unique BGP. Further, the initial conditions with respect

\footnotetext{
${ }^{2}$ The ${ }^{\star}$ denotes values on the BGP.
} 
to $K, G$ and $B$ are given while initial consumption, $C(0)$, can be chosen freely. Thus, the economy is saddle point stable when there are two negative eigenvalues of the Jacobian matrix of the system (11)-(13).

The Jacobian matrix is given by,

$$
J=\left[\begin{array}{ccc}
y & y(1-\alpha) x^{-\alpha}\left(\alpha(1-\tau)-\left(1-i_{p}\right)\right) & 0 \\
x & x^{1-\alpha}\left((-\alpha) x^{-1} i_{p}-\left(1-i_{p}\right)(1-\alpha)\right) & 0 \\
b & \partial \dot{b} / \partial b & r(1-\tau)-g-\psi
\end{array}\right]
$$

One eigenvalue of that matrix is given by $\lambda_{1}=r(1-\tau)-g-\psi$ which is negative for $\psi>r(1-\tau)-g$. In the case of a balanced budget that eigenvalue is always negative since a balanced budget implies $\psi=r(1-\tau)$.

The other two eigenvalues are the eigenvalues of the matrix $J_{1}$,

$$
J_{1}=\left[\begin{array}{cc}
y & y(1-\alpha) x^{-\alpha}\left(\alpha(1-\tau)-\left(1-i_{p}\right)\right) \\
x & x^{1-\alpha}\left((-\alpha) x^{-1} i_{p}-\left(1-i_{p}\right)(1-\alpha)\right)
\end{array}\right]
$$

The determinant is $\operatorname{det} J_{1}=x y\left((-\alpha) x^{-\alpha-1} i_{p}-\alpha(1-\alpha)(1-\tau) x^{-\alpha}\right)<0$. Since the determinant is negative, the dynamic system (11)-(13) is saddle point stable for $\lambda_{1}<0$.

\section{Conclusion}

In this note we have analyzed stability effects of different debt policies for quite a general class of endogenous growth models. We have seen that a discretionary fiscal policy always implies that the inter-temporal budget constraint of the government is violated while a balanced government budget tends to stabilize the economy. With a rule based policy the debt to GDP ratio remains bounded when the reaction of the primary surplus to higher public debt is sufficiently large. In deriving the latter result, the assumption that the government adjusts non-distortionary transfer payments was essential. However, we conjecture that the latter outcome also holds when public spending is adjusted instead of 
transfer payments. That cannot be proven in general but, nevertheless, holds for many models (see e.g. Greiner, 2007, Greiner, 2008, or Greiner, 2011).

\section{Appendix}

\section{Proof of proposition 1}

The debt to private capital ratio evolves according to

$$
\dot{b}=b r(1-\tau)-\frac{S}{K}-b\left(\frac{\dot{K}}{K}\right)=b\left(\frac{\rho+r(1-\tau)(\sigma-1)}{\sigma}\right)-\frac{S}{K},
$$

where we used $\dot{K} / K=(-\rho+r(1-\tau)) / \sigma$ on a BGP. Since the primary surplus is not a function of public debt, neither the growth rate of capital nor that of consumption depend on public debt. Further, taking into account that $r$ and $S / K$ are constant on a BGP, the solution to the differential equation is given by,

$$
b(t)=\frac{S / K}{(\rho+r(1-\tau)(\sigma-1)) / \sigma}+e^{t(\rho+r(1-\tau)(\sigma-1)) / \sigma}\left(b(0)-\frac{S / K}{(\rho+r(1-\tau)(\sigma-1)) / \sigma}\right) .
$$

Noting that $\dot{K} / K=g=(-\rho+r(1-\tau)) / \sigma$ holds on a BGP, we get for the level of public debt

$$
B(t)=K_{0} e^{g t}\left(C_{1}+C_{2} e^{r(1-\tau) t-g t}\right)
$$

with $C_{1}=\sigma(S / K) /(\rho+r(1-\tau)(\sigma-1))$ and $C_{2}=b_{0}-\sigma(S / K) /(\rho+r(1-\tau)(\sigma-1))$.

Thus, for $r(1-\tau)>g \leftrightarrow \rho+r(1-\tau)(\sigma-1)>0$ the limit of the present value of public debt is given by,

$$
\lim _{t \rightarrow \infty} e^{-r(1-\tau) t} B(t)=K_{0} C_{2} .
$$

This shows that the limit of the present value is positive (negative) if the initial primary surplus falls short (exceeds) the initial level of public debt multiplied by the difference between the net interest rate and the balanced growth rate, i.e. if $S_{0}<(>) B_{0}(r(1-\tau)-g)$ holds. If the limit of the present value is negative, the private sector is a borrower and 
fails to pay back its (gross) debt. The case $S_{0}=B_{0}(r(1-\tau)-g)$ has Lebesgue measure zero and, therefore, is not generic. If the government sets $S_{0}$ intentionally such that the latter equality holds, the fiscal policy cannot be termed a discretionary one.

For $r(1-\tau)<g \leftrightarrow \rho+r(1-\tau)(\sigma-1)<0$ the limit of the present value of public debt is obtained as,

$$
\lim _{t \rightarrow \infty} e^{-r(1-\tau) t} B(t)=+\infty \quad(-\infty), \quad \text { for } \quad S<0 \quad(S>0)
$$

If the present value of public debt diverges to minus infinity, the transversality condition in the optimization problem of the household is violated.

\section{Proof of proposition 2}

To prove proposition 2 we first note that in case of a balanced government budget the debt to GDP ratio evolves according to

$$
\dot{b}=b(0-\dot{K} / K)
$$

Differentiating with respect time and using $b^{\star}=0$ yields,

$$
\frac{\partial \dot{b}}{\partial b}=\left(0-\frac{\dot{K}}{K}\right)-b^{\star}\left(\frac{\partial(\dot{B} / B)}{\partial b}-\frac{\partial(\dot{K} / K)}{\partial b}\right)=-\frac{\dot{K}}{K}=-g
$$

The Jacobian matrix evaluated at the rest point is given by

$$
J_{2}=\left[\begin{array}{cccc}
\ldots & \ldots & \ldots & \ldots \\
\vdots & \vdots & \vdots & \vdots \\
0 & \ldots & 0 & -g
\end{array}\right]
$$

Thus, one eigenvalue of the Jacobian is $-g$.

\section{Proof of proposition 3}

With the primary surplus rule, the debt to capital ratio evolves according to

$$
\dot{b}=b\left(\frac{\dot{B}}{B}-\frac{\dot{K}}{K}\right)
$$


with $\dot{B} / B=r(1-\tau)-\psi-\phi b^{-1}(Y / K)$ and $\dot{K} / K=\left(Y-C-G_{p}\right) / K$. Differentiating with respect to $b$ yields

$$
\begin{aligned}
\frac{\partial \dot{b}}{\partial b} & =\left(\frac{\dot{B}}{B}-\frac{\dot{K}}{K}\right)+b\left(\frac{\partial(\dot{B} / B)}{\partial b}-\frac{\partial(\dot{K} / K)}{\partial b}\right)= \\
& =r(1-\tau)-\psi-\phi b^{-1}(Y / K)-g+b \phi b^{-2}(Y / K)=r(1-\tau)-\psi-g
\end{aligned}
$$

where we used $\dot{K} / K=g$. This shows $\partial \dot{b} / \partial b>(<) 0$ for $\psi<(>) r(1-\tau)-g$.

With the primary surplus rule, the Jacobian matrix evaluated at the rest point is

$$
J_{3}=\left[\begin{array}{cccc}
\ldots & \ldots & \ldots & 0 \\
\vdots & \vdots & \vdots & \vdots \\
\vdots & \vdots & \vdots & 0 \\
\ldots & \ldots & \ldots & r(1-\tau)-g-\psi
\end{array}\right]
$$

Thus, one eigenvalue of the Jacobian is equal to $r(1-\tau)-g-\psi$.

\section{References}

Benhabib, J. and R.E.A. Farmer, (1994) "Indeterminacy and increasing returns." Journal of Economic Theory, Vol. 63: 19-94.

Blanchard, O.J. and S. Fischer (1989) Lectures on Macroeconomics. The MIT Press, Cambridge, Mass.

Bohn, H. (1998) "The behavior of U.S. public debt and deficits." Quarterly Journal of Economics, Vol. 113: 949-63.

Greiner, A. (2007) "An endogenous growth model with public capital and sustainable government debt." Japanese Economic Review, Vol. 58: 345-61.

Greiner, A. (2008) "Does it pay to have a balanced government budget?" In: Journal of Institutional and Theoretical Economics (JITE), Vol. 164: 460-76. 
Greiner, A. (2011) "Economic growth, public debt and welfare: Comparing three budgetary rules." In: German Economic Review, Vol. 12: 205-22.

Greiner, A. Köller, U. and W. Semmler (2007) "Debt Sustainability in the European Monetary Union: Theory and Empirical Evidence for Selected Countries." Oxford Economic Papers, Vol. 59: 194-218.

Schmitt-Grohé, S. and U. Uribe (1997) "Balanced-budget rules, distortionary taxes, and aggregate instability." Journal of Political Economy, Vol. 105, 976-00. 